\title{
Positioning of umbilical arterial catheters with ultrasound
}

\author{
A K GARG, A B HOUSTON, J M LAING, AND J R MACKENZIE \\ Departments of Neonatal Paediatrics and Radiology, Royal Maternity Hospital, Glasgow
}

SUMMARY Fifty six infants were studied by ultra-
sound, 22 during the placement of the umbilical
artery catheter. The descending aorta, bifurcation,
common iliac arteries, and the intra-arterial catheter
could be clearly seen. We recommend that the
catheter tip be placed $5-10 \mathrm{~mm}$ above the aortic
bifurcation thus avoiding the major branches of
descending aorta.

Catheterisation of the umbilical artery is a routine procedure to facilitate management of sick or potentially ill neonates. Accurate placement of the catheter should minimise complications, but until now there has been no simple method to determine correctly the catheter position in relation to the aorta and its branches.

\section{Patients, method, and results}

Fifty six newborn infants were studied. Their weights ranged from $0.725 \mathrm{~kg}-3.54 \mathrm{~kg}$ and gestational age from 26 weeks to term. The ultrasonic equipment was a Toshiba SAL 20 linear array real time scanner fitted with a $5 \mathrm{MHz}$ probe. The transducer was placed in the posterior axillary line between the rib cage and the iliac crest and adjusted to provide optimum image. The abdominal aorta was seen as two parallel linear echoes with an echo free space between, and regular change in calibre indicated pulsation. It was then followed inferiorly to image the bifurcation and the common iliac arteries and superiorly to the level of the diaphragm, which was recognised by its movement in time with respiration.

Umbilical arterial catheterisation was performed in 22 infants under aseptic conditions using either a neonatal oxygen probe (Searle) or a catheter (Argyle-Sherwood) of size 4 or 5 FG. In all 56 infants it was possible to image the descending aorta from above the diaphragm down to and including the bifurcation and the common iliac arteries (Figure). In infants undergoing catheterisation the intra-arterial catheter was imaged as a linear echo dense structure. The tip was clearly identified and its position in relation to the bifurcation noted. The position on the radiograph did not bear a constant relation to the distance of the catheter tip from the bifurcation.

Four babies were studied at necropsy to determine

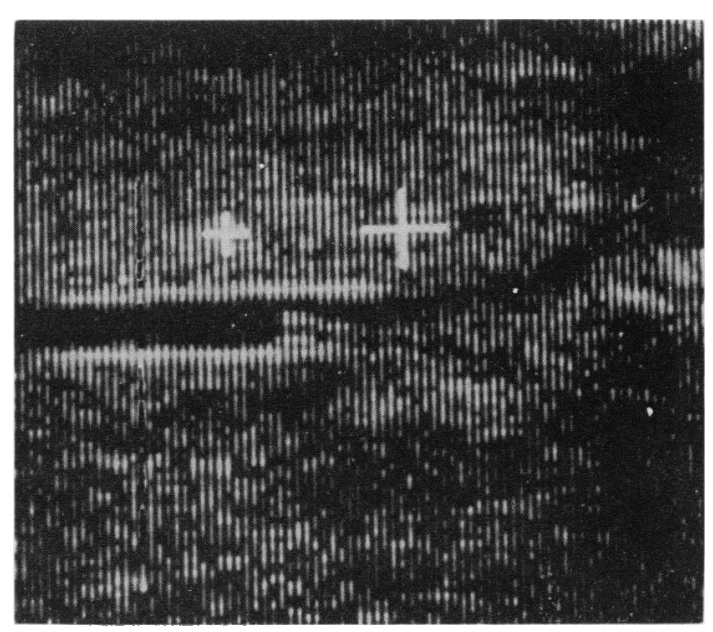

Figure Ultrasound image of the abdominal aorta and the catheter tip. The crosses are distance markers $10 \mathrm{~mm}$ apart. The catheter tip is positioned $6 \mathrm{~mm}$ above the bifurcation.

the relation of the origin of the inferior mesenteric artery to the aortic bifurcation. In three infants (weight $0 \cdot 88-1 \cdot 33 \mathrm{~kg}$ ) this distance was $10-15 \mathrm{~mm}$ and in one with spina bifida (weight $1.12 \mathrm{~kg}$ ) it was $6 \mathrm{~mm}$.

\section{Discussion}

The recommended position for the tip of an umbilical arterial catheter is either in the lower thoracic aorta or the abdominal aorta just above the bifurcation, and for the abdominal position of the catheter, the level of the third lumbar vertebra or just below is recommended to avoid the renal and inferior mesenteric vessels. ${ }^{1}$ Until now the position could only be checked indirectly by radiography.

The aorta most frequently bifurcates at the fourth lumbar vertebra but in $40 \%$ of cases this occurs at a higher or lower level. ${ }^{2}$ Phelps et al..$^{2}$ concluded that using the present technique of catheter placement and radiological confirmation might lead to an error in the positioning of the tip of up to $15 \mathrm{~mm}$ on either side of the bifurcation. Thus, even if a radiograph shows the catheter in a satisfactory position, it is possible that the tip is in a common iliac artery or in 
close proximity to the origin of the inferior mesenteric artery. Animal studies have shown laminar flow in the aorta and toxic damage to the mucosa after infusion of hyperosmolar solutions. ${ }^{3}$

Accurate placement in relation to the aortic bifurcation may be achieved with ultrasound imaging. This dispenses with the need for a confirmatory radiograph, reducing the total radiation to the infant. Failure to visualise the catheter in the iliac artery will indicate that it has been inadvertently placed in the umbilical vein or outside the arterial system. From our experience with an infant in whom thrombosis associated with an intra-arterial catheter was recognised, we believe that regular ultrasonic examination should help in the assessment of this complication.

With the established value of real time ultrasound scanning in neonatology and the increasing availability of the equipment, this technique is now feasible in most neonatal units. We therefore recommend that an umbilical arterial catheter should be inserted under ultrasound screening and the tip placed 5-10 $\mathrm{mm}$ above the aortic bifurcation. A confirmatory radiograph is not required.

\section{References}

1 Cockburn F, Drillen CM. Neonatal medicine. Oxford: Blackwell Scientific Publications, 1974.

2 Phelps DL, Lachman RS, Leake RD, Oh W. The radiologic localization of the major aortic tributaries in the newborn infant. J Pediatr 1972;81:336-9.

3 Book LS, Herbst JJ. Intra-arterial infusions and intestinal necrosis in the rabbit: potential hazards of umbilical artery injections of ampicillin, glucose, and sodium bicarbonate. Pediatrics 1980;65:1145-9.

Correspondence to Dr A B Houston, Department of Neonata Paediatrics, Royal Maternity Hospital, Glasgow G4.

Received 30 August 1983

\title{
Fatal, low renin hypertension associated with a disturbance of cortisol metabolism
}

\author{
J W HONOUR, M J DILLON, M LEVIN, AND V SHAH \\ Division of Clinical Chemistry, MRC Clinical Research Centre, Harrow, and Hospital for \\ Sick Children, Great Ormond Street, London
}

SUMMARY A 5 month old boy died after fever, persistently raised blood pressure, and hypokalaemia. A disorder of cortisol metabolism caused by $11 \beta$ hydroxysteroid dehydrogenase deficiency was detected retrospectively.

Hypertension associated with renal potassium wasting and alkalosis in children is usually renin dependent, with secondary hyperaldosteronism. When renin and aldosterone production are suppressed this type of clinical presentation may occur where there is (a) increased adrenal production or mineralocorticoid hormones are being given; (b) ingestion of compounds with mineralocorticoid activity, such as liquorice; or (c) a disorder of electrolyte homeostasis, such as Liddle's syndrome. ${ }^{1}$ The latter is a rare, familial cause of hypertension ascribed to a generalised disorder of ion transport ${ }^{2}$ in which the raised blood pressure and electrolyte disturbance may be corrected by triamterine. In other similar disorders a mineralocorticoid excess state may be suggested by a favourable clinical response to the mineralocorticoid antagonist, spironolactone. ${ }^{3}$ Specific investigation of children with this disorder has shown subnormal production of identifiable mineralocorticoid hormones and cortisol partly caused by a defect of the $11 \beta$-hydroxysteroid dehydrogenase, which is normally responsible for peripheral equilibration of cortisol with the less active cortisone. ${ }^{4}$ We report a 5 month old boy who seems to be the youngest child identified with $11 \beta$-hydroxysteroid dehydrogenase deficiency, and the first fatal case.

\section{Case report}

A boy, the second child of healthy, unrelated parents was delivered by caesarean section at 37 weeks' gestation because of poor fetal growth. Birthweight was $2.36 \mathrm{~kg}$ and the placenta was small and infarcted. Apgar scores were 6 at 1 minute and 9 at 5 minutes. In the neonatal period he had prolonged hyperbilirubinaemia, for which no cause was found. The maximum bilirubin was $230 \mu \mathrm{mol} / \mathrm{l}$ $(13.4 \mathrm{mg} / 100 \mathrm{ml})$ on day 5 of life. This seemed to settle spontaneously but at age 1 month the child was investigated again because mild jaundice persisted. 